via the ducts, and analogous to the changes met with in chronic pancreatitis. Another case of great interest in the series, and belonging to Group $\Lambda$, is also quoted :-

CASE 3.-Carcinoma of tongue. Male, aged 72 years. A feeble man with a large soft fungating ulcer on the left side of the dorsum lingua ; no impairment of tongue movements. Many enlarged and hard glands felt on both sides of the neck. Wassermann reaction +++ .

Microscopical Examination of ulcer: Squamous-celled carcinoma.

Block dissection of neck was carried out; patient died of shock.

Microscopical Examination.-Tissues removed included many apparently malignant and much enlarged lymph nodes from all parts of the neck. Salivary glands : submaxillary, chronic inflammation; sublingual, no changes. Lymph nodes (submaxillary, submental, carotid, and infrahyoid) : Chronic inflammation, with endothelial-celled infiltration. No evidence of carcinoma.

Here, then, is a case where the extensive removal of chronically inflamed though clinically malignant tissue led to the death of an enfeebled patient who might, and probably would, have survived removal of the tongue alone by the intrabuccal route. Two other cases of an exactly similar nature have recently come under our observation.

\section{Lymph Nodes.}

Anatomy. - In regard to the anatomical grouping of the lymph nodes in the submaxillary region, it would appear to follow that described by stahr ${ }^{3}$ and confirmed by Dobson and Jamieson ${ }^{4}$ in so far as our observations go. There seem to be, in addition to the normally palpable groups of nodes situated in the cellular tissue around the gland, innumerable small nodes not to be detected by the naked eye under ordinary conditions, but which on malignant or septic infection enlarge and become visible. Indeed, the enlargement and spread of these microscopic nodes of lymphoid tissue, lying amongst the fibro-adipose connective tissue, can be fully observed in pathological processes in the human subject as a result of infection, both septic and malignant.

These superficial nodes, normally few in number, are arranged in two main groups, one around the facial vein and another on a deeper plane between the mylo-hyoid muscle and the deep surface of the anterior end of the superficial lobe of the submaxillary gland. There is, moreover, a third group of glands, not invariably obvious under normal conditions, which must be borne in mind by the surgeon in all these cases-namely, the group deep to the deep lobe of the submaxillary gland and lying along the lingual and vena comes nervi hypoglossi, between the gland and the hypoglossus muscle, just above the great corner of the hyoid bone.

In addition to the above superficial groups four or five nodes occur embedded in the substance of the salivary gland, apparently definitely encapsuled, and usually occurring in conjunction with the interlobular veins. There are, however, in these inflamed salivary glands many areas of leucocytic infiltration, which may well have given rise to the statement that lymph nodes existed in large numbers within the gland capsule. It would appear that all these groups of lymphatic nodes lie without, though closely incorporated with, the capsule of the salivary gland, and that the lobules of the gland overlap and surround the lymph nodes, as they do the reins along which these nodes lie.

\section{Surgical Inferences.}

Inasmuch as the group of nodes deep to the deep lobe of the gland drain directly from the side of the tongue, they are presumably much more likely to become infected with carcinoma than the more superficial groups, and inasmuch as their anatomical situation renders them difficult of approach and excision by the surgeon, they are of especial interest in these cases. Moreover, as a result of observations on salivary glands removed, it would seem that in many cases only the superficial lobe is excised, the deep lobe being left in situ with its accompanying deep group of lymph nodes. It would seem from the results quoted in the table that the submaxillary lymph nodes frequently escape carcinomatous infection (71 per cent. in carly and 50 per cent. in late cases in this series), though in all cases they show inflammatory changes in and around their substance. This is a point of some practical interest, as it raises the question whether it is justifiable in cases of carcinoma to leave this area untouched, which would preserve the floor of the mouth and lessen both the severity of the operation and the danger of postoperative complications.

In view of the fact that even in early cases there is invasion of the lymph nodes in the submaxillary region in nearly 30 per cent. of cases, it is obviously unjustifiable to leave the area untouched, except under exceptional circumstances, such as in a very debilitated or very aged patient, where it is justifiable to take the risk of the subsequent development of metastases which may follow such conservative measures. Such cases should, of course, be carefully watched for any sign of malignant disease occurring in the nodes in the region after removal of the primary focus. As regards any operation for the conservation of the salivary gland, with dissection and removal of the lymph nodes, the anatomical grouping of the nodes clearly renders their efficient removal impossible unless the salivary gland is also excised, and inasmuch as the removal of this would appear to be followed by no untoward results, there would seem to be no justification for abandoning or even modifying the various operative measures at present in vogue.

\section{Conclusions.}

1. That in the vast majority of cases of carcinoma of tongue and floor of mouth the salivary glands are not the seat of carcinoma.

2 . That in nearly all cases the changes present in these glands are of a chronic inflammatory nature, somewhat analogous to the changes met with in the pancreas in chronic pancreatitis, and apparently due to infection from the mouth along the ducts. In other cases no microscopic change can be seen.

3 . That the lymph nodes in this area show malig. nant changes in only $27 \cdot 3$ per cent. of early and 50 per cent. of late cases, though inflammation is alwas s present. It would appear, therefore, in certain cases with early carcinoma of tongue to be justifiable to leave the submaxillary area untouched at operation, though clinical experience teaches that the risk of the subsequent appearance of metastases is very great.

References.-1. Butlin, H. T.: Diseases of Tongue, p. 334. 3 Stahr: Arch. f. Anat. u. Physiol., 1898.4. Jamieson, J. Kav. and Dobson, J. F.: British Journal of Surgery, vol, viii

\section{PERIODIC ALKALEMIA WITH ALKALOSIS IN THE ADULT.}

By WILLIAM MACADAM, M.A., M.D.GLASG., M.R.C.P. LoND.,

LECTURER IN I'ATHOLOGY, UNIVERSTTY OF IEEDS;

$$
\text { AND }
$$

JOHN GORDON, M.B., CH.B. LEEDS,

DEMONSTRATOR IN PATHOLOGY, UNIVRRSITY OF IEEDS.

CycLIC vomiting in children is quite well recognised clinically, but owing to its relative rarity of occurrence and the difficulties of chemical investigation in children there is little definite knowledge as to the metabolism of the condition. For the last 18 months we have had under observation in an adult a condition which clinically appeared to be a metabolic disturbance similar to that recognised in the cyclic vomiting of children. The case was thought worthy of as complete a metabolic study as possible; we have now had the opportunity of making observations during seven attacks, and have investigated the condition from different metabolic standpoints-i.e., liver disturbance, pancreatic disturbance, abnormal carbo- 
hydrate metabolism, renal efficiency, intestinal intoxication, \&c. Observations of considerable interest have been obtained from work along these lines, and will subsequently be published.

The most fruitful findings, however, have resulted from a study of the acid-base equilibrium of the blood, for they appear to furnish fairly conclusive evidence that the condition present in this particular case is one of alkalæmia with alkalosis, and not of acidosis, as has been generally accepted in conditions of cyclic vomiting. Furthermore, this conclusion is confirmed by the results of treatment directed to counteract the alkalosis.

\section{Clinical Summary of Case.}

A. S., male, aged 39, engineer, had always been healthy (except for an attack of acute appendicitis at the age of 30 , for which appendicectomy was performed), until four years ago when there commenced a series of " bilious attacks" lasting about a fortnight and separated by intervals of three months or so.

Course of a Typical Attack. - The first symptoms are usually a frontal headache, and feeling of listlessness, and later a dull aching pain in the lumbar region. After a varying interval, sometimes of several days, vomiting of a non-explosive character begins and continues for 4-7 days, while there is a complaint of pain and tenderness across the abdomen
above the umbilicus. The attack generally ends with a drowsy semi-comatose condition, lasting 12-24 hours, and usually ushered in by a short period of intense vomiting. The average duration of an attack is 10-14 days, the patient's recovery and return of strength being as rapid as is the onset of the illness. There is associated a moderate degree of fever of remittent type, reaching a maximum of $101^{\circ}-102^{\circ} \mathrm{F}$. and lasting 5-7 days. Pulse-rate lies between $72-84$ and respirations average 18-24 per minute. There is no dyspnoea and no air-hunger. There is nothing of special note about the vomitus, which is clear watery fluid, with no great excess of mucus and containing no free hydrochloric acid. Towards the end of the vomiting stage there is a considerable amount of bile present.

Family History.-No history of migraine or of any nervous stigmata can be obtained.

Urinary Findings.-These first suggested to us that a complete study of the acid-base balance of the blood might afford useful information. Acetonuria is constantly present during the whole period of illness in the various attacks. The amount of " acetone bodies" is not excessive, quantitative estimation (Embden's method) giving an average excretion never exceeding $1 \mathrm{~g}$. of acetone plus aceto-acetic acid per 24 hours. We have satisfied ourselves that the acetonuria appears before the factors of fasting and vomiting have time to assert themselves. Thus we have repeatedly noticed that a morning specimen of urine, examined because the man suffered from headache and other prodromal symptoms, might be quite free from diacetic acid (Rothera's test). While a specimen passed in the early afternoon of the same day would give a "quick-strong" reaction, and such a finding was invariably the precursor of a typical attack as described above.

It may be noted that the urine during the intervals between the attacks has been examined at least once a week for the last 18 months, and acetonuria has never been observed except when an attack was imminent.

\section{Remarks.}

The most striking feature of the urinary examination during the attacks, from the very commencement of our observations, has been that the ammonia output or rather the ammonia index-i.e., amount of ammonia nitrogen reckoned as a percentage of the total nitrogen-was consistently lower than normalviz., 2-4 per cent., instead of being considerably increased, 10-20 per cent., or even higher, as in most cases of acetonuria with acidosis.

Davies, Haldane, and Kennaway, ${ }^{1}$ in some recent experimental work, have shown that a distinct acetonuria can be produced by the administration of large doses of sodium bicarbonate $(30-50$ g. per 24 hours). Since, in all previous attacks before coming into hospital, the patient had been heavily dosed with alkalies, by mouth, by stomach tube, and per rectumthe usually accepted treatment for such conditions of recurrent vomiting-and since during the first attack under observation in hospital the alkalies administered were of negligible amount, we wondered whether in view of the low ammonia index, the absence of alkali medication had led to a milder attack than had been previously experienced. Attention was therefore concentrated on a study of the acid-base equilibrium of the blood.

L. J. I Ienderson ${ }^{2}$ has shown that the actual reaction of the blood at any particular time under any particular set of circumstances depends on the ratio: Free $\mathrm{CO}_{2}$ concentration. Normally this ratio averages $1 / 20$. When the value is increased, the blood reaction becomes less alkaline than normal, or a condition of acidæmia is produced. This increase in value may be brought about either by an increase in the numerator, or by a decrease in the denominator -i.e., of the alkali reserve-in other words by an acidosis.

On the other hand, when the value of the ratio is decreased, the blood reaction becomes more alkaline than normal - that is, a condition of alkaloemia results. This may be due either to a decrease in the numerator - a condition which may result from hyperpnoea, or experimental forced breathing, or to an increase in the $\mathrm{CO}_{2}$ combining power of the blood plasma, and it is for the designation of this latter condition of increased "alkali reserve" that the name alkalosis should be altogether reserved. It is as thus defined that the terms alkalæmia and alkalosis are used in the present paper. A very excellent and lucid account of the modern meaning of "blood reaction," and of the mechanism of its regulation was published recently by Lovatt Evans. ${ }^{3}$

\section{Methods of Investigation Employed.}

The data obtained from our investigations of the combined and free $\mathrm{CO}_{2}$ of the blood in this case of periodic vomiting, corroborate our deductions from the urinary findings. During the three attacks of sickness and vomiting thus investigated a condition of alkalæmia associated with alkalosis has been found to be present.

The methods employed were the following :- $-1 . \mathrm{CO}_{2}$ tension of alveolar air: Haldane and Priestley's method. 4 2. Alkali reserve of venous blood plasma: Van Slyke and Cullen's ${ }^{5} 6$ technique. 3. Hydrogen-ion concentration of arterial blood: Dale and Evans's? method. 4. Basic and acid phosphates of urine: Leathes's ${ }^{8}$ double titration method. 5. Total nitrogen of urine : Kjeldahl. 6. Ammonia nitrogen of urine: Folin, Sovensen. 7. Acetone and aceto-acetic acid : Embden.

\section{Observations Recorded.}

In Table I. are given the data of the urinary and blood investigations of attack 6 , which bear upon the question of the acid-base balance. The protocols of the previous attacks show similar findings; this one is selected because estimations of the $\mathrm{CO}_{2}$ tension of the alveolar air and of the alkali reserve of the blood plasma were simultaneously recorded, while treatment by the oral administration of decinormal hydrochloric acid was also carried out.

We also record the data of the blood and respiratory analysis for the succeeding attack (Table II.), as it was the first occasion on which we were enabled to carry out the estimation of the arterial blood hydrogenion concentration. The urinary analyses are not tabulated, as the findings are similar to those of the previous attacks.

It will be seen from Table $I$. that the $\mathrm{CO}$, tension of alveolar air is distinctly subnormal-viz., $31.9 \mathrm{~mm}$. and $32.5 \mathrm{~mm}$. in the second and sixth days of illness, as compared with $38.5 \mathrm{~mm}$.- an observation made during the interval of apparent good health. A similar low value- $32 \cdot 1 \mathrm{~mm}$.-was obtained on the fifth day of illness of the next attack before any treatment was exhibited. The "alkali-reserve" of the blood-plasma is high, 72 vols. and 64 vols. per cent., the normal usually being taken as 50-60 vols. per cent. It is to be noted that the alkali reserve of this man appeared to be consistently high-values as high as 78 and 74 vols. per cent. being obtained. in a series of observations made while the patient was in normal health. No explanations of these high values can be offered at present. The technique in no 
way differed from that with which numerous findings both within the usually accepted normal range and also values below 50 vols. per cent. have been obtained.

We have, however, collected a series of pathological conditions in which the alkali reserve of the blood plasma has been surprisingly high and we hope to be able to correlate these later. Certainly this man exhibits a condition of alkalosis, using the word in its strict sense. It is further seen that the $\mathrm{pH}$ of the arterial blood on the fifth day of the attack was distinctly raised, pointing to increased alkalinity, while a normal value was obtained during the period of normal health. It is to be remembered, as Evans ${ }^{9}$ has pointed out, that the indicator method devised altered acid-base balance of the blood. For four or five weeks before the probable date of an attack of vomiting, \&c., we carried out a fractional test-meal examination (Rehfuss's meal) each Sunday morning. The several findings showed notbing of special note except the variations in type and height of curve for total acidity and free $\mathrm{HCl}$ which may occur from week to week in the same individual. On the morning of the last examination of our series the man seemed to have a heavy lethargic look, and on questioning him he adrritted suffering from headache and feeling "oft colour" for the previous 24 hours. Examination of the urine revealed a definite acetonuria, which marked the beginning of a typical attack. The interesting

Table I.-Altack 6 .

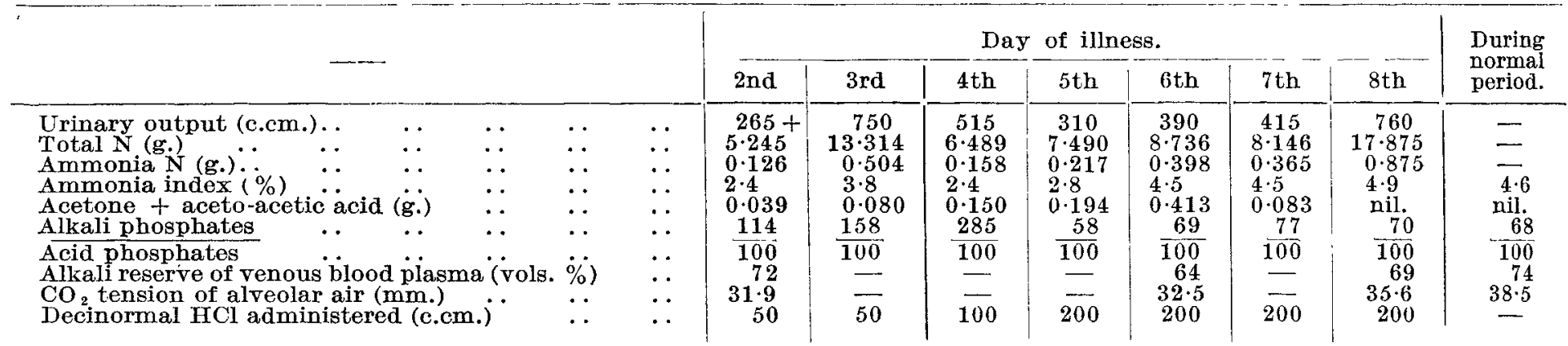

\begin{tabular}{|c|c|c|c|c|}
\hline \multicolumn{5}{|c|}{ TABLE II.-Attack $\gamma}$. \\
\hline Date. & $\begin{array}{c}\text { pH ar. } \\
\text { terial } \\
\text { blood. }\end{array}$ & $\begin{array}{l}\mathrm{CO}_{2} \text { ten- } \\
\text { sion alv. } \\
\text { air. }\end{array}$ & $\begin{array}{c}\text { Alkali } \\
\text { reserve } \\
\text { venous } \\
\text { plasma. }\end{array}$ & Remarks. \\
\hline $\begin{array}{l}4 / 4 / 22 \text { (fifth day } \\
\text { of illness). }\end{array}$ & $7 \cdot 7$ & $32 \cdot 1 \mathrm{~mm}$. & $67 \%$ & No attempt at \\
\hline $21 / 4 / 22 \quad \cdots$ & $7 \cdot 65$ & - & $78 \%$ & $\begin{array}{l}\text { Patient had felt } \\
\text { quite well for } \\
10 \text { days. }\end{array}$ \\
\hline
\end{tabular}

by Dale and himself gives a $\mathrm{pH}$ which is regularly 0.2 higher than that obtained by the electrometric method, the normal blood reaction, according to the latter being taken as $\mathrm{pH} 7 \cdot 3-7 \cdot 5$. The values obtained by us in a series of 30 normal cases have been between pH $7 \cdot 64-7 \cdot 66$, using Dale and Evans's technique.

Thus when we take the ratio $\frac{\mathrm{CO}_{2}}{\mathrm{NaHCO}_{3}}$, as explained above, we find that during the attacks of periodic sickness there is simultaneously a low value for the numerator, and a high value for the denominatora condition which should be associated with an abnormally alkaline reaction of the blood or an alkalæmia, and the presence of this condition has been demonstrated by direct observation-viz., pH 7.70. As to the urinary acidity, although we have made a full investigation by various methods of both titratable acidity and the actual $\mathrm{pH}$, we are not disposed to lay any stress on the findings, nor to make any deductions therefrom in the present communication. We have, however, recorded in Table I. our findings of the ratio of basic phosphates to acid phosphates, as estimated by the double titration method suggested by Leathes. ${ }^{8}$ We do so because they illustrate a phenomenon which we have repeatedly observed in many of the attacks. There is a relatively large excretion of basic phosphates as compared with the acid phosphates during the first few days of the illness, suggesting an attempt on the part of the kidneys to get rid of the abnormally high "alkali reserve." This is followed by a sudden reversal of the ratio to the more normal state of affairs when the basic phosphates amount to 1-3 of the acid phosphates. This is well shown by the figures recorded in Table I., where basic-acid ratios $114 \quad 158 \quad 285$ $\frac{114}{100}, \frac{158}{100}, \frac{285}{100}$ on the second, third, and fourth days of illness, are followed by ratios of $\frac{58}{100}, \frac{69}{100}, \frac{77}{100}$.

We also made another observation which we think worthy of note in connexion with this condition of

point about the gastric analysis on this the first (or at most the second) day of the attack, was the high total acidity and free $\mathrm{HCl}$ - considerably higher than in any of the previous test-meal examinations. Thus a total acidity of 70 (measured in terms of c.cms. N/10 NaOH per 100 c.cm. gastric filtrate) was maintained during the second hour of the test-meal examination, while the maximum height of the total acidity curve in the previous three examinations had ranged from 25-50. This depletion of acid from blood and body tissues would all tend to accentuate the condition of alkalosis.

Treatment with Decinormal Hydrochloric Acid.

On the strength of the above observations pointing to an abnormally alkaline blood reaction, the patient was treated during attacks 5 and 6 with moderately large doses of decinormal hydrochloric acid. The difficulty was to get the patient to take the desired amount, owing to the repeated vomiting. From the second day in attack 5 , and the fifth day in attack 6 , he took $200 \mathrm{c.cm}$. N/10 acid (110 m Ac.hydrochloric. dil. B.P.). These attacks lasted six and seven days respectively, and were shorter than any of those occurring during the last two years. It has to be recollected, however, that it is exceedingly difficult to change the "alkali reserve" of the blood by ingestion of hydrochloric acid $b_{5}$ the mouth, although the acid and ammonia excretion per hour is thereby increased. Recently, J. B. S. Haldane ${ }^{0}$ has demonstrated that an acidosis can be experimentally produced by the administration of ammonium chloride. This salt appears, in part, to undergo changes in the body, the ammonia going to form urea, thus setting free some hydrochloric acid, and aiding the production of an acidosis.

During the last attack observed-attack 7-an attempt was made, from the fifth day of illness, to treat the patient with this drug ( 240 gr. per 24 hours). Unfortunately, however, it was found that the irritable condition of the stomach would not tolerate one quarter of the above amount, even in small and frequently repeated doses, and a much more satisfactory result was obtained by the exhibition of hydrocbloric acid as described above in the two previous attacks.

Although a condition of alkalæmia with alkalosis appears to have been conclusively demonstrated in this case of recurrent or cyclic vomiting in an adult, we are very far from suggesting that this is the type of acid-base derangement always present in cases of cyclic vomiting. The very fact that treatment by alkalies, especially when administered very early in 
the attack, leads to beneficial results in many cases of recurrent vomiting in children is satisfactory evidence that a condition of acidosis may also occur. We suggest, however, that a disturbance of the acidbase balance towards the alkaline side instead of towards the acid side may also occur, and indeed may be more common than is supposed in various conditions of toxæmia.

To the clinician acetonuria has usually suggested acidosis. We now know, as Davies, Haldane, and Kennaway ${ }^{1}$ have demonstrated, that acetone bodies may appear in the urine as the result of the administration of large doses of alkalies; while the case under review shows that they may be associated with an alkalæmia. We would also suggest that an investigation along similar lines of various conditions of metabolic disturbance may prove fruitful in revealing a swing of the acid-base balance to the alkaline side. Mention may be made, for example, of certain toxæmias of pregnancy associated with vomiting, of which Gilliatt and Kennaway ${ }^{11}$ have given a full account. They give records of their own cases and cite those of Ewing and of Whitridge Williams, which, owing to the unexplained low or even subnormal ammonia index, have frequently been considered of "neurotic" origin as contrasted with those showing an abnormally high ammonia index.

A study of migraine, and indeed of a simple "bilious attack," might also be of interest, while an explanation of some of the unsatisfactory results following the administration of large doses of alkalies in certain conditions of acetonuria may thus be afforded. Although a condition of alkalæmia with alkalosis has been demonstrated in this case of cyclic vomiting, we have to admit that, so far, we are no nearer the discovery of the definitive cause of those periodic attacks associated with this change of the acid-base balance of the blood.

\section{Conclusions.}

1. A case is described of periodic vomiting in an adult, aged 39, which has continued over a period of five years. In addition to a constant acetonuria during the attacks, the other notable feature of the urinary examination is an abnormally low ammonia index.

2. Investigations of the blood and alveolar air show that during the attacks of sickness there is a low hydrogen-ion concentration of the blood, a low $\mathrm{CO}_{2}$ tension of the alveolar air, and a high $\mathrm{CO}_{2}$ combining power of the blood-plasma-in fine, a condition of alkalæmia with alkalosis.

3. Treatment with large doses of decinormal hydrochloric acid, to counteract this abnormal alkaline reaction of the blood and body tissues, gave satisfactory results ; the administration of ammonium chloride was unsuccessful owing to vomiting being immediately induced.

4. The clinical association of acetonuria with a condition of alkalæmia is thus demonstrated, and corroborates the similar experimental findings of Davies, Haldane, and Kennaway.

5. It is possible that these findings afford an explanation of some of the unsatisfactory results following the administration of large doses of alkalies in certain conditions of acetonuria; while it is suggested that some of those metabolic disturbancese.g., certain types of the toxæmia of pregnancy-in which a low ammonia index has been associated with severe clinical symptoms may be due to the swing of the acid-base balance of the blood to the alkaline side.

In conclusion, we desire to express our thanks to Dr. G. W. Watson, physician to the Leeds General Infirmary, for his kindness in handing the case over to us and in placing a bed at our disposal for conducting our observations during the several attacks of illness. We.wish also to express our indebtedness to Prof. M. J. Stewart, in whose department the work has been carried out; to Prof. H. S. Raper, of the Physiology Department, for valuable assistance and advice ; and to Miss E. M. Hickman for help in carrying out some of the later investigations.

(Continued at foot of next column.)

\section{THE SCOPE OF VACCINE THERAPY.}

BY C. E. JENKINS, M.R.C.S. ENG., PATHOLOGIST, GALFORD ROYAL MOSPITAL.

THE utility and limitations of vaccine therapy are questions which resolve themselves into a consideration of two interdependent factors - the patient and the vaccine. It will be convenient to discuss them together. All cases which can be treated by vaccints are divisible into three main groups : the division is of more importance than mere academic classification, for the success of the treatment will often depend upon the discrimination of the clinician or the bacteriologist in allotting a case to its correct group. The first group comprises the cases in which cure or alleviation of a disease actually present is desired. To the second group belong that large mass of healthy people who require a vaccine for prophylactic purposes-that is to say, to acquire protection against some disease which may attack them at a future date. The third group is the one which causes confusion. To it belong the cases which require prophylaxis primarily, but which at the same time are in need of cure.

\section{The Suitable Cases.}

Group 1.- It is a commonplace that the two cardinal requirements of a successful vaccine are that the disease it is proposed to treat shall be a bacterial disease, and that the vaccine shall be prepared from the causal organism. Even so, success cannot be guaranteed. Other subsidiary factors, although separately of small moment, exert collectively a very important influence upon the final result. First, the patient's condition must be capable of improvement, for no vaccine can repair, or rather recreate, a tissue already completely destroyed. Thus a vaccine will frequently benefit a case of long-standing chronic bronchitis to the extent of abolishing the dyspnoea, asthmatic attacks, cough, and that anæmia which frequently accompanies the condition. But it cannot be expected to cure the emphysema, the presence of which is a standing and irremovable threat of future trouble if the patient becomes too confident of his powers of resistance and therefore careless. It is hardly necessary to observe that such factors as age, opportunity of rest, and undermining of resistance by long toxic absorption all count in the ultimate result. Alcoholic excess is a well-known predisposing cause of bacterial invasion, both acute and chronic, but it has often to be pointed out to the patient that whilst the vaccine may cure his present illness it is unlikely to confer upon him what he would regard as the high privilege of a permanent and absolute immunity from all the unpleasant effects of strong drink.

Another type of case often benefited by raccine therapy comprises those sufferers from a disease in which one sets out frankly to treat a secondary infection or a complication, leaving the primary cause to the patient to deal with as best he may. Such conditions as the valvular lesions of the heart com plicated by chronic bacterial pulmonary infection are of this nature. The fact that in most cases the cardiac lesion had a bacterial origin is beside the point. The damage has been done, the causal organism has disappeared, and all one can do is to mitigate the damage. Pulmonary tuberculosis of what is called the "open" type is another example. Here the primary disease is complicated by secondary An abstract of a post-graduate lecture delivered at the
Salford Royal Hospital.

\section{(Continued from previous column.)}

References.-1. Davies, Haldane, and Kennaway : Jour. Physiol., 1920, liv., 32. 2. Henderson, L. J. : Ergebn. der

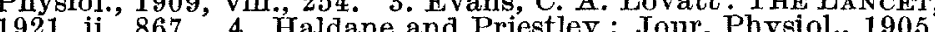
1921, ii., 867. 4. Haldane and Priestley : Jour. Physiol., 1905,

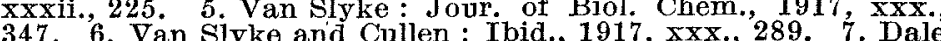
347. 6. Van Slyke and Cullen : Ibid., 1917, xxx., 289. 7. Dale and Evans: Jour. Physiol, 1920, liv., 167. 8. Leathes: Brit. Med. Jour., 1919, ii., 165. 9. Evans: Jour. Physiol., 1920, Giviliatt and Kennaway: Quart. Jour. Med., 1919, xi.., 61. 